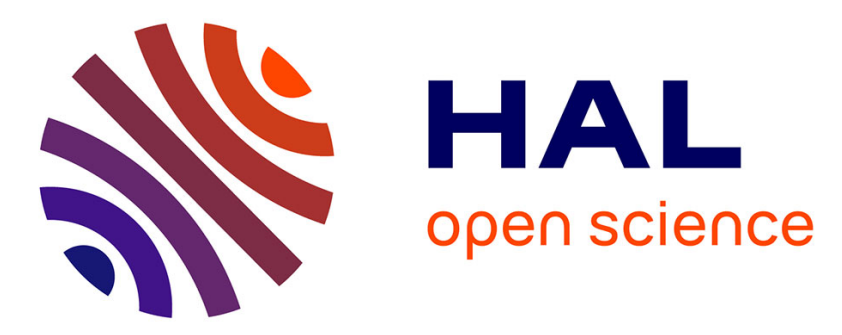

\title{
Adaptive observer for fault estimation in nonlinear systems described by a Takagi-Sugeno model
}

\author{
Atef Kheder, Kamel Benothman, Mohamed Benrejeb, Didier Maquin
}

\section{To cite this version:}

Atef Kheder, Kamel Benothman, Mohamed Benrejeb, Didier Maquin. Adaptive observer for fault estimation in nonlinear systems described by a Takagi-Sugeno model. 18th Mediterranean Conference on Control and Automation, MED'10, Jun 2010, Marrakech, Morocco. pp.CDROM. hal-00497786

\section{HAL Id: hal-00497786 https://hal.science/hal-00497786}

Submitted on 9 Apr 2014

HAL is a multi-disciplinary open access archive for the deposit and dissemination of scientific research documents, whether they are published or not. The documents may come from teaching and research institutions in France or abroad, or from public or private research centers.
L'archive ouverte pluridisciplinaire HAL, est destinée au dépôt et à la diffusion de documents scientifiques de niveau recherche, publiés ou non, émanant des établissements d'enseignement et de recherche français ou étrangers, des laboratoires publics ou privés. 


\title{
Adaptive observer for fault estimation in nonlinear systems described by a Takagi-Sugeno model
}

\author{
Atef Khedher, Kamel Benothman, Mohamed Benrejeb and Didier Maquin
}

\begin{abstract}
This paper deals with the problem of fault estimation for linear and nonlinear systems. An adaptive proportional integral observer is designed to estimate both the system state and sensor and actuator faults which can affect the system. The model of the system is first augmented in such a manner that the original sensor faults appear as actuator faults in this new model. The faults are then considered as unknown inputs and are estimated using a classical proportional-integral observer. The proposed method is first developed for linear systems and is then extended to nonlinear ones that can be represented by a Takagi-Sugeno model. In the two cases, examples of low dimensions illustrate the effectiveness of the proposed method.
\end{abstract}

Index Terms - fault diagnosis, fault estimation, adaptive observer, proportional-integral observer, state estimation, TakagiSugeno model

\section{INTRODUCTION}

State estimation is an important field of research with numerous applications in control and diagnosis. Generally the whole system state is not always measurable and the recourse to its estimation is a necessity.

An observer is generally a dynamical system allowing the state reconstruction from the system model and the measurements of its inputs and outputs [15]. For linear models, state estimation methods are very efficient [5], [13], [14]. However for many real systems, the linearity hypothesis cannot be assumed. In that case, the synthesis of a nonlinear observer allows the reconstruction of the system state. For example, let us cite sliding mode observers [4], the Thau-Luenberger observers [21] and observer for nonlinear systems described by Takagi-Sugeno models [2].

Approaches using Takagi-Sugeno model (also known as multiple model [17]) are the object of many works in different contexts including the taking into account of unknown inputs or parameter uncertainties [1], [7], [8]. Various studies dealing with the presence of unknown inputs acting on the system were published [1], [5], [20]. Some of them tried to reconstruct the system state in spite of the unknown input existence. This reconstruction is assured via the elimination of unknown inputs [6], [20]. Other works

Atef Khedher, Kamel Benothman and Mohamed Benrejeb are with LARA Automatique, ENIT, BP 37, le Belvédère, 1002 Tunis, khedher_atef@yahoo.fr, kamel. benothmandenim. rnu.tn, mohamed.benrejeb.enit.rnu.tn

Didier Maquin is with the CRAN, UMR 7039, Nancy-Université, CNRS, 2, avenue de la Forêt de Haye, 54516 Vandœuvre-lès-Nancy, didier.maquindensem.inpl-nancy. fr choose to estimate, simultaneously, the unknown inputs and system state [1], [5], [18]. Among the techniques that do not require the elimination of the unknown inputs, Wang [23] proposes an observer able to entirely reconstruct the state of a linear system in the presence of unknown inputs and in [16], to estimate the state, a model inversion method is used. Using the Walcott and Zak structure observer [22] Edwards et al. [3], [4] have also designed a convergent observer using the Lyapunov approach.

Observers with unknown inputs are used to estimate actuator faults which can be considered as unknown inputs. This estimation can be obtained using a proportional integral observer [12], [19]. In most cases, a physical process can be subjected to disturbances which have as origin the noises due to its environment, uncertainty of measurements, sensor and/or actuator faults. These disturbances have harmful effects on the normal behavior of the process and their estimation can be used to conceive a control strategy able to minimize their effects. In the case of sensor faults, Edwards [5] proposes, for linear systems, to use a new state which is a filtered version of the output, to conceive an augmented system in which the sensor faults appear as unknown inputs. This formulation was also used by [9]-[11], [24] to be able to estimate the faults.

In many cases, systems are affected by faults of different nature such as sensor or actuator faults, so, in this paper, a proportional integral observer is conceived to estimate, simultaneously, the state and theses two kind of faults. The extension of this method to nonlinear systems described by Takagi-Sugeno models is proposed thereafter.

The paper is organised as follows. Section II presents the proposed method of faults estimation for linear systems. In section III the extension of the proposed method for nonlinear systems described by Takagi-Sugeno models is made. Two simulations examples are proposed to validate the method for linear and nonlinear systems.

\section{LINEAR SYSTEM CASE}

The objective of this part is to estimate a fault affecting a linear system via an adaptive proportional integral state observer. 


\section{A. Problem formulation}

Consider the linear model affected by a sensor fault, an actuator fault and a measurement noise described by:

$$
\begin{aligned}
\dot{x}(t) & =A x(t)+B u(t)+E f_{a}(t) \\
y(t) & =C x(t)+F f_{s}(t)+D w(t)
\end{aligned}
$$

where $x(t) \in \mathbb{R}^{n}$ represents the system state, $y(t) \in \mathbb{R}^{m}$ is the measured output, $u(t) \in \mathbb{R}^{r}$ is the known system input, $f_{a}(t)$ and $f_{s}(t)$ represent respectively actuator and sensor faults and $w(t)$ is the measurement noise. $A, B$ and $C$ are known constant matrices with appropriate dimensions. $E, F$ and $D$ are respectively the actuator fault, the sensor fault and the noise distribution matrices which are assumed to be known. Consider also the state $z(t) \in \mathbb{R}^{p}$ that is a filtered version of the output $y(t)$ [5]. This state is given by:

$$
\dot{z}(t)=-\bar{A} z(t)+\bar{A} C x(t)+\bar{A} F f_{s}(t)+\bar{A} D w(t)
$$

where $-\bar{A} \in \mathbb{R}^{p \times p}$ is a stable matrix. Let us introduce the augmented state $X(t)=\left[x^{T}(t) z^{T}(t)\right]^{T}$ and the corresponding augmented system given by:

$$
\begin{aligned}
& \dot{X}(t)=A_{a} X(t)+B_{a} u(t)+E_{a} f(t)+F_{a} w(t) \\
& Y(t)=C_{a} X(t)
\end{aligned}
$$

with:

$$
\begin{aligned}
& A_{a}=\left[\begin{array}{cc}
A & 0 \\
\bar{A} C & -\bar{A}
\end{array}\right], B_{a}=\left[\begin{array}{c}
B \\
0
\end{array}\right], E_{a}=\left[\begin{array}{cc}
E & 0 \\
0 & \bar{A} F
\end{array}\right] \\
& F_{a}=\left[\begin{array}{c}
0 \\
\bar{A} D
\end{array}\right], C_{a}=\left[\begin{array}{ll}
0 & I
\end{array}\right], f(t)=\left[\begin{array}{l}
f_{a}(t) \\
f_{s}(t)
\end{array}\right]
\end{aligned}
$$

The structure of the chosen observer is as follows:

$$
\left\{\begin{array}{l}
\dot{\hat{X}}(t)=A_{a} \hat{X}(t)+B_{a} u(t)+E_{a} \hat{f}(t)+K \tilde{Y}(t) \\
\dot{\hat{f}}(t)=L \tilde{Y}(t) \\
\hat{Y}(t)=C_{a} \hat{X}(t)
\end{array}\right.
$$

where $\hat{X}(t)$ is the estimated augmented state, $\hat{f}(t)$ represents the estimated fault, $\hat{Y}(t)$ is the estimated output, $K$ is the proportional observer gain and $L$ is the integral gain to be computed. $\tilde{Y}(t)=Y(t)-\hat{Y}(t)$. Let us define the state estimation error $\tilde{x}(t)$ and the fault estimation error $\tilde{f}(t)$ :

$$
\tilde{x}(t)=X(t)-\hat{X}(t) \text { and } \tilde{f}(t)=f(t)-\hat{f}(t)
$$

The dynamics of the state estimation error is given by the computation of $\dot{\tilde{x}}(t)$ which can be written:

$$
\begin{aligned}
\dot{\tilde{x}}(t) & =\dot{X}(t)-\dot{\hat{X}}(t) \\
& =\left(A_{a}-K C_{a}\right) \tilde{x}(t)+E_{a} \tilde{f}(t)+F_{a} w(t)
\end{aligned}
$$

The dynamics of the fault estimation error is:

$$
\begin{aligned}
\dot{\tilde{f}}(t) & =\dot{f}(t)-\dot{\hat{f}}(t) \\
& =\dot{f}(t)-L C_{a} \tilde{x}(t)
\end{aligned}
$$

Let us introduce:

$$
\varphi(t)=\left[\begin{array}{c}
\tilde{x}(t) \\
\tilde{f}(t)
\end{array}\right] \text { and } \varepsilon(t)=\left[\begin{array}{c}
w(t) \\
\dot{f}(t)
\end{array}\right]
$$

From (7) and (8), one can obtain:

$$
\dot{\varphi}(t)=A_{0} \varphi(t)+B_{0} \varepsilon(t)
$$

with:

$$
A_{0}=\left[\begin{array}{cc}
A_{a}-K C_{a} & E_{a} \\
-L C_{a} & 0
\end{array}\right] \text { and } B_{0}=\left[\begin{array}{cc}
F_{a} & 0 \\
0 & I
\end{array}\right]
$$

In order to analyse the convergence of the generalized estimation error $\varphi(t)$, let us consider the following quadratic Lyapunov candidate function $V(t)$ :

$$
V(t)=\varphi^{T}(t) P \varphi(t)
$$

where $P$ denotes a positive definite matrix.

The problem of robust state and fault estimation reduces to finding the gains $K$ and $L$ of the observer to ensure an asymptotic convergence of $\varphi(t)$ toward zero if $\varepsilon(t)=0$ and to ensure a bounded error when $\varepsilon(t) \neq 0$, i.e.:

$$
\begin{array}{ll}
\lim _{t \rightarrow \infty} \varphi(t)=0 & \text { for } \varepsilon(t)=0 \\
\|\varphi(t)\|_{Q_{\varphi}} \leq \lambda\|\varepsilon(t)\|_{Q_{\varepsilon}} & \text { for } \varepsilon(t) \neq 0
\end{array}
$$

where $\lambda>0$ is the attenuation level. To satisfy the constraints (13), it is sufficient to find a Lyapunov function $V(t)$ such that:

$$
\dot{V}(t)+\varphi^{T}(t) Q_{\varphi} \varphi(t)-\lambda^{2} \varepsilon^{T}(t) Q_{\varepsilon} \varepsilon(t)<0
$$

where $Q_{\varphi}$ and $Q_{\varepsilon}$ are two positive definite matrices.

The inequality (14) can also be written as:

$$
\psi(t)^{T} \Omega \psi(t)<0
$$

with:

$$
\psi(t)=\left[\begin{array}{c}
\varphi(t) \\
\varepsilon(t)
\end{array}\right], \Omega=\left[\begin{array}{cc}
A_{0}^{T} P+P A_{0}+Q_{\varphi} & P B_{0} \\
B_{0}^{T} P & -\lambda^{2} Q_{\varepsilon}
\end{array}\right]
$$

The quadratic form in (15) is negative if $\Omega<0$. The matrix $A_{0}$ can be expressed as:

$$
A_{0}=\tilde{A}-\tilde{K} \tilde{C}
$$

with:

$$
\tilde{A}=\left[\begin{array}{cc}
A_{a} & E_{a} \\
0 & 0
\end{array}\right], \tilde{K}=\left[\begin{array}{c}
K \\
L
\end{array}\right], \tilde{C}=\left[\begin{array}{ll}
C_{a} & 0
\end{array}\right]
$$

The presence of the terms $P \tilde{K}$ and $\lambda^{2}$ let the inequality $\Omega<0$ nonlinear, to linearize it, let us define the following changes of variables $G=P \tilde{K}$ and $m=\lambda^{2}$. The matrix $\Omega$ can then be written as:

$$
\Omega=\left[\begin{array}{cc}
P \tilde{A}+\tilde{A}^{T} P-G \tilde{C}-\tilde{C}^{T} G^{T}+Q_{\varphi} & P B_{0} \\
B_{0}^{T} P & -m Q_{\varepsilon}
\end{array}\right]
$$

The resolution of the inequality $\Omega<0$, that is now linear with regard to the different unknowns, leads to find the matrices $P$ and $G$ and the scalar $m$. The gain matrix $\tilde{K}$ is determined via the resolution of $\tilde{K}=P^{-1} G$ and the attenuation level $\lambda$ is given by $\lambda=\sqrt{m}$. 


\section{B. Example}

Let us consider the linear system described by the following matrices:

$$
\begin{gathered}
A=\left[\begin{array}{cccc}
-0.3 & -3 & -0.5 & 0.1 \\
-0.7 & -5 & 2 & 4 \\
2 & -0.5 & -5 & -0.9 \\
-0.7 & -2 & 1 & -0.9
\end{array}\right], B=\left[\begin{array}{cc}
1 & 2 \\
5 & 1 \\
4 & -3 \\
1 & 2
\end{array}\right], \\
D=\left[\begin{array}{cc}
0.5 & 0.5 \\
0.2 & 0.2 \\
0.1 & 0.1 \\
0 & 0.1
\end{array}\right], F=\left[\begin{array}{cc}
4 & 6 \\
0 & 0 \\
-4 & 2 \\
7 & 6
\end{array}\right]
\end{gathered}
$$

$C=I$ and $E=B$. The system input $u(t)$ is defined by $u(t)=\left[\begin{array}{ll}u_{1}^{T}(t) & u_{2}^{T}(t)\end{array}\right]^{T}$, where $u_{1}(t)$ is a telegraph type signal varying between zero and one and $u_{2}(t)$ is defined by $u_{2}(t)=0.4+0.25 \sin (\pi t)$. The actuator fault $f_{a}(t)$ is made up of two components

$$
f_{a}(t)=\left[\begin{array}{ll}
f_{a 1}^{T}(t) & f_{a 2}^{T}(t)
\end{array}\right]^{T}
$$

with:

$$
\begin{gathered}
f_{a 1}(t)=\left\{\begin{array}{ll}
0.4 \sin (\pi t), & 15 s<t<75 s \\
0, & \text { otherwise }
\end{array},\right. \\
f_{a 2}(t)= \begin{cases}0, & t<20 s \\
0.3, & 20 s<t<80 s \\
0.5, & t>80 s\end{cases}
\end{gathered}
$$

and the sensor fault $f_{s}(t)$ is defined as follows:

$$
f_{s}(t)=\left[\begin{array}{ll}
f_{s 1}^{T}(t) & f_{s 2}^{T}(t)
\end{array}\right]^{T}
$$

with:

$f_{s 1}(t)=\left\{\begin{array}{ll}0, & t \leq 35 s \\ 0.6, & t>35 s\end{array}, f_{s 2}(t)= \begin{cases}0, & t \leq 25 s \\ \sin (0.6 \pi t), & t>25 s\end{cases}\right.$

To define the state $z$, one choose $\bar{A}=25 \times I$, where $I$ is the identity matrix.

Using the previously described method with $Q_{\varphi}=Q_{\epsilon}=I$ leads to the obtention of the observer gain $K$ and $L$. The resulting attenuation level is $\lambda=0.3162$ and:

$$
\begin{aligned}
K & =\left[\begin{array}{cccc}
116.0253 & -40.0901 & -23.0977 & -37.0989 \\
-16.9977 & 78.3129 & 30.9322 & 56.9434 \\
-161.4062 & 149.2055 & 4.9692 & 135.7089 \\
112.4707 & -74.5075 & 34.8011 & -91.8975 \\
12.0452 & 18.2418 & -3.6436 & 25.1209 \\
-2.9528 & 22.0100 & 6.1366 & 22.9357 \\
6.0123 & -2.7081 & 5.2831 & -1.9449 \\
0.5412 & -3.6433 & 2.3397 & 8.0328
\end{array}\right] \\
L & =\left[\begin{array}{cccc}
-76.7558 & 122.3517 & 22.1039 & 125.0592 \\
185.6710 & -104.5700 & -37.2061 & -17.9442 \\
6.9387 & -25.9424 & -107.0508 & 152.6953 \\
49.4870 & -71.5776 & 56.8719 & 108.1356
\end{array}\right]
\end{aligned}
$$

The simulation results are shown in the figures 1 and 2 . This method allows to estimate well the faults affecting the system even in the case of time-varying faults.
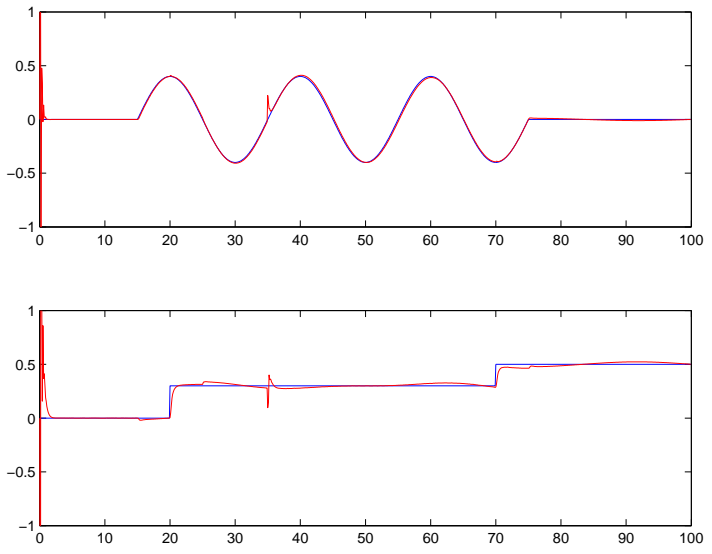

Fig. 1. Actuator faults and their estimation
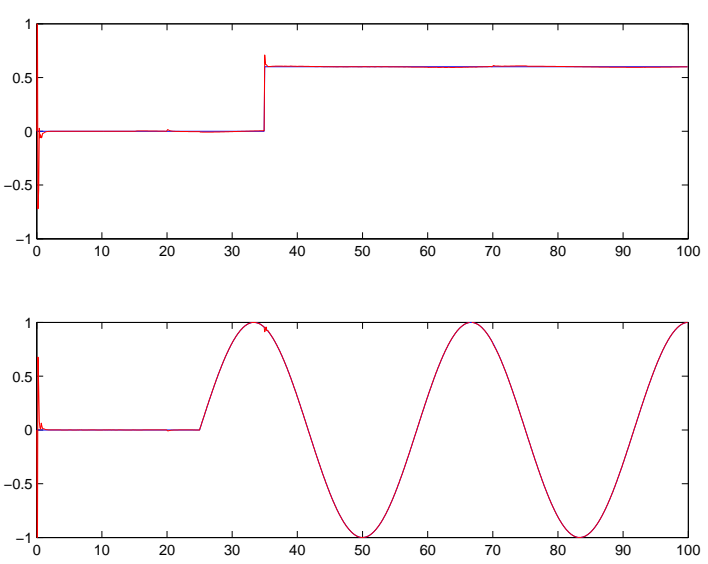

Fig. 2. Sensor faults and their estimation

\section{EXTENSION TO MULTIPLE MODEL REPRESENTATION}

The objective of this part is to extend the previous proposed method to nonlinear systems represented by a TakagiSugeno model.

\section{A. Problem formulation}

Consider the following nonlinear Takagi-Sugeno system affected by sensor faults, actuator faults and a measurement noise described by:

$$
\begin{aligned}
& \dot{x}(t)=\sum_{i=1}^{M} \mu_{i}(\xi(t))\left(A_{i} x(t)+B_{i} u(t)+E_{i} f_{a}(t)\right)(22 \\
& y(t)=C x(t)+F f_{s}(t)+D w(t)
\end{aligned}
$$

where $x(t) \in \mathbb{R}^{n}$ represents the system state, $y(t) \in R^{m}$ is the measured output, $u(t) \in \mathbb{R}^{r}$ is the system input, $f_{a}(t)$ and $f_{s}(t)$ represents respectively actuator and sensor faults and $w(t)$ is the measurement noise. $A_{i}, B_{i}$ and $C$ are known constant matrices with appropriate dimensions. $E_{i}, F$ and $D$ are respectively the actuator faults, the sensor 
faults and the noise distribution matrices which are assumed to be known. The scalar $M$ represents the number of local models. The weighting functions $\mu_{i}$ are nonlinear and depend on the decision variable $\xi(t)$ which must be measurable. The weighting functions satisfy the convex sum property expressed in the following equations:

$$
0 \leq \mu_{i}(\xi(t)) \leq 1, \quad \sum_{i=1}^{M} \mu_{i}(\xi(t))=1
$$

Let us consider the state $z \in \mathbb{R}^{p}$ given by:

$\dot{z}(t)=\sum_{i=1}^{M} \mu_{i}(\xi(t))\left(-\bar{A}_{i} z(t)+\bar{A}_{i} C x(t)+\bar{A}_{i} F f_{s}(t)+\bar{A}_{i} D w(t)\right)$

where $-\bar{A}_{i}, \quad i \in 1, . ., M$ are stable matrices. The dynamics of the augmented state $X(t)=\left[\begin{array}{ll}x^{T}(t) & z^{T}(t)\end{array}\right]^{T}$ is governed by:

$$
\begin{gathered}
\dot{X}(t)=\sum_{i=1}^{M} \mu_{i}(\xi(t))\left(A_{a i} X(t)+B_{a i} u(t)+E_{a i} f(t)+F_{a i} w(t)\right) \\
Y(t)=C_{a} X(t)
\end{gathered}
$$

with:

$$
\begin{gathered}
A_{a i}=\left[\begin{array}{cc}
A_{i} & 0 \\
\bar{A}_{i} C & -\bar{A}_{i}
\end{array}\right], B_{a i}=\left[\begin{array}{c}
B_{i} \\
0
\end{array}\right], \\
E_{a i}=\left[\begin{array}{cc}
E & 0 \\
0 & \bar{A}_{i} F
\end{array}\right], F_{a i}=\left[\begin{array}{c}
0 \\
\bar{A}_{i} D
\end{array}\right]
\end{gathered}
$$

The matrices $C_{a}$ and $f$ are given by the equation (4). The structure of the proportional integral observer is chosen as follows:

$$
\begin{gathered}
\dot{\hat{X}}(t)=\sum_{i=1}^{M} \mu_{i}(\xi(t))\left(A_{a i} \hat{X}(t)+B_{a i} u(t)+E_{a i} \hat{f}(t)+K_{i} \tilde{Y}(t)\right) \\
\hat{f}(t)=\sum_{i=1}^{M} \mu_{i}(\xi(t)) L_{i} \tilde{Y}(t) \\
\hat{Y}(t)=C_{a} \hat{X}(t)
\end{gathered}
$$

where $\hat{X}(t)$ is the estimated system state, $\hat{f}(t)$ represents the estimated fault, $\hat{Y}(t)$ is the estimated output, $K_{i}$ are the local model proportional observer gains and $L_{i}$ are the local model integral gains to be computed and $\tilde{Y}(t)=Y(t)-\hat{Y}(t)$.

Using the expressions of $\tilde{x}(t)$ and $\tilde{f}(t)$ given by the equation (6), the dynamics of the state reconstruction error is given by:

$$
\dot{\tilde{x}}(t)=\sum_{i=1}^{M} \mu_{i}(\xi(t))\left(\left(A_{a i}-K_{i} C_{a}\right) \tilde{x}(t)+E_{a i} \tilde{f}(t)+F_{a i} w(t)\right)
$$

The fault estimation error can be expressed as:

$$
\dot{\tilde{f}}(t)=\dot{f}(t)-\sum_{i=1}^{M} \mu_{i}(\xi(t)) L_{i} C_{a} \tilde{x}(t)
$$

Using the definitions of $\varphi$ and $\varepsilon$ given in (9) and omitting to denote the dependance with regard to the time $t$, the equations (31) and (32) can be written:

$$
\dot{\varphi}=A_{m} \varphi+B_{m} \varepsilon
$$

with:

$$
A_{m}=\sum_{i=1}^{M} \mu_{i}(\xi) \tilde{A}_{0 i} \text { and } B_{m}=\sum_{i=1}^{M} \mu_{i}(\xi) \tilde{B}_{0 i}
$$

where:

$$
\tilde{A}_{0 i}=\left[\begin{array}{cc}
A_{a i}-K_{i} C_{a} & E_{a i} \\
-L_{i} C_{a} & 0
\end{array}\right], \tilde{B}_{0 i}=\left[\begin{array}{cc}
F_{a i} & 0 \\
0 & I
\end{array}\right]
$$

By considering the Lyapunov function $V(t)$ given in (12), and following the same reasoning as for linear systems, convergence of state and fault estimation errors as well as attenuation level are guaranteed if:

$$
\psi(t)^{T} \Omega_{m} \psi(t)<0
$$

with:

$$
\psi=\left[\begin{array}{l}
\varphi \\
\varepsilon
\end{array}\right], \Omega_{m}=\left[\begin{array}{cc}
A_{m}^{T} P+P A_{m}+Q_{\varphi} & P B_{m} \\
B_{m}^{T} P & -\lambda^{2} Q_{\varepsilon}
\end{array}\right]
$$

The inequality (36) holds if $\Omega_{m}<0$. Following the same steps as for the linear case, let us define:

$$
A_{0 i}=\tilde{A}_{i}-\tilde{K}_{i} \tilde{C}
$$

with:

$$
\tilde{A}_{i}=\left[\begin{array}{cc}
A_{a i} & E_{a i} \\
0 & 0
\end{array}\right], \tilde{K}_{i}=\left[\begin{array}{c}
K_{i} \\
L_{i}
\end{array}\right], \tilde{C}=\left[\begin{array}{ll}
C_{a} & 0
\end{array}\right]
$$

Using the changes of variables $G_{i}=P \tilde{K}_{i}$ and $m=\lambda^{2}$, the matrix $\Omega_{m}$ can be written as:

$$
\Omega_{m}=\sum_{i=1}^{M} \mu_{i}(\xi(t)) \Omega_{i}
$$

with:

$$
\Omega_{i}=\left[\begin{array}{cc}
P \tilde{A}_{i}+\tilde{A}_{i}^{T} P-G_{i} \tilde{C}-\tilde{C}^{T} G_{i}^{T}+Q_{\varphi} & P B_{m} \\
B_{m}^{T} P & -m Q_{\varepsilon}
\end{array}\right]
$$

Sufficient conditions ensuring the negativity of $\Omega_{m}$ can be expressed as:

$$
\Omega_{i}<0, \quad \forall i \in\{1, \ldots, M\}
$$

Solving LMI's (42) leads to the determination of the matrices $P$ and $G_{i}$ and the scalar $m$. The gain matrices are then deduced: $\tilde{K}_{i}=P^{-1} G_{i}$.

\section{B. Example}

Consider the nonlinear system described by a the TakagiSugeno model given by the equation (22) with:

$$
\begin{aligned}
& A_{1}= {\left[\begin{array}{cccc}
-0.3 & -3 & -0.5 & 0.1 \\
-0.7 & -5 & 2 & 4 \\
2 & -0.5 & -5 & -0.9 \\
-0.7 & -2 & 1 & -0.9
\end{array}\right], B_{1}=\left[\begin{array}{cc}
1 & 2 \\
5 & 1 \\
4 & -3 \\
1 & 0
\end{array}\right] } \\
& A_{2}= {\left[\begin{array}{cccc}
-0.7 & -7 & -1.5 & -7 \\
-0.2 & -2 & 0.6 & 1.3 \\
5 & -1.5 & -9 & -3.9 \\
-0.4 & -1 & -0.3 & -1
\end{array}\right], B_{2}=\left[\begin{array}{cc}
1 & 1 \\
2 & 1 \\
0 & 2 \\
-1 & -2
\end{array}\right] } \\
& D=\left[\begin{array}{cc}
0.5 & 0.5 \\
0.2 & 0.2 \\
0.1 & 0.1 \\
0 & 0.1
\end{array}\right], F=\left[\begin{array}{cc}
3.25 & 5 \\
0 & 0.5 \\
-3.25 & 1.75 \\
5.75 & 5
\end{array}\right] \\
& E_{1}=B_{1}, E_{2}=B_{2}, M=2, \xi(t)=u(t), C=I
\end{aligned}
$$


Considering $u(t)=\left[\begin{array}{ll}u_{1}(t) & u_{2}(t)\end{array}\right]^{T}$, the signal $u_{1}(t)$ is a telegraph type signal whose amplitude belongs to the interval $[0,0.5]$. The signal $u_{2}(t)$ is defined by $u_{2}(t)=0.4+0.25 \sin (\pi t)$. The fault signals $f_{a}(t)$ and $f_{s}(t)$ are given by the equations (20) and (21).

Choosing $Q_{\varphi}=Q_{\epsilon}=I, \bar{A}_{1}=5 \times I$ and $\bar{A}_{2}=10 \times I$, the set of LMI (42) can be solved, leading to the determination of the different gains of the proposed observer: $\lambda=3.3166$ and

$$
\begin{aligned}
K_{1}= & {\left[\begin{array}{cccc}
21.7261 & -5.3236 & -16.5771 & -43.8763 \\
-6.4652 & 53.0576 & -2.8775 & 2.0534 \\
-30.8514 & 56.1659 & -10.6775 & 46.8992 \\
-18.6032 & -8.8603 & 10.1258 & -24.4917 \\
17.1705 & -2.4699 & -8.9768 & -8.2040 \\
3.0258 & 10.0009 & -1.7346 & 2.1461 \\
2.9950 & -0.0968 & 3.4689 & -0.2700 \\
-0.3535 & -0.4946 & -0.0403 & 4.6610
\end{array}\right] } \\
K_{2}= & {\left[\begin{array}{cccc}
25.7725 & -48.4503 & -10.4671 & -33.1388 \\
-41.2285 & 139.0493 & 3.4662 & 10.8503 \\
-61.0689 & 183.0421 & 19.4017 & 36.0392 \\
-3.8613 & -25.6660 & 9.6924 & -4.3148 \\
15.4687 & -23.0853 & -7.4343 & -11.5565 \\
-0.8234 & 22.9419 & 1.1660 & 1.3886 \\
2.3609 & 0.8733 & -2.5571 & 0.0073 \\
-0.7383 & 0.4161 & 1.0880 & 0.5716
\end{array}\right] } \\
L_{1}= & {\left[\begin{array}{cccc}
9.4356 & 55.9749 & -0.3767 & 29.5858 \\
65.1988 & -19.9203 & 0.8819 & -35.5076 \\
5.0431 & 5.9123 & -32.3952 & 75.0141 \\
22.6533 & -19.8043 & 32.9891 & 57.6045
\end{array}\right] } \\
L_{2}= & {\left[\begin{array}{cccc}
-38.0795 & 158.8227 & 4.1724 & 16.5804 \\
62.4301 & -113.0505 & -19.4454 & -43.9582 \\
-4.2585 & 33.6689 & -33.0954 & 46.4728 \\
19.5100 & -47.1125 & 9.7380 & 27.7166
\end{array}\right] }
\end{aligned}
$$

The simulation results are shown in the figures 3 to 5 . As for the previous linear case, the proposed method provides good estimates of the system state (Figure 3 shows the four state estimation errors), and the faults affecting the system (Figure 4 presents the actuators faults and their estimation while Figure 5 depicts the sensor faults).

\section{CONCLUSION}

This communication has presented an adaptive proportional integral observer able to estimate simultaneously actuator and sensor faults. Initially developed for linear models (simple case), the design has been extended to nonlinear models through the use of Takagi-Sugeno model. Small size examples have illustrated the efficiency of the proposed approach either for constant and time-varying faults. For the considered examples, the matrices which filter the output of the actual system has been chosen on an empirical manner. Further research work would include the analysis of the influence of this extra dynamics with regard to the noise acting on the system and the specifications of fault detection problem. Clearly, the obtained fault estimates could also be used through a fault tolerant control law.
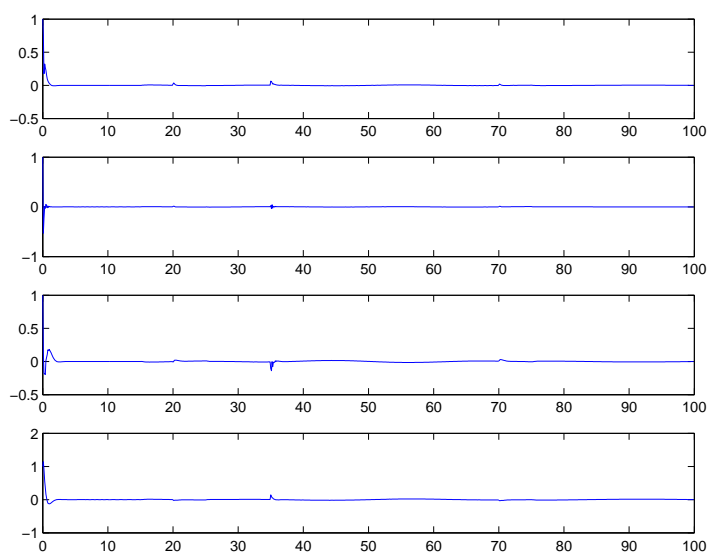

Fig. 3. State estimation errors
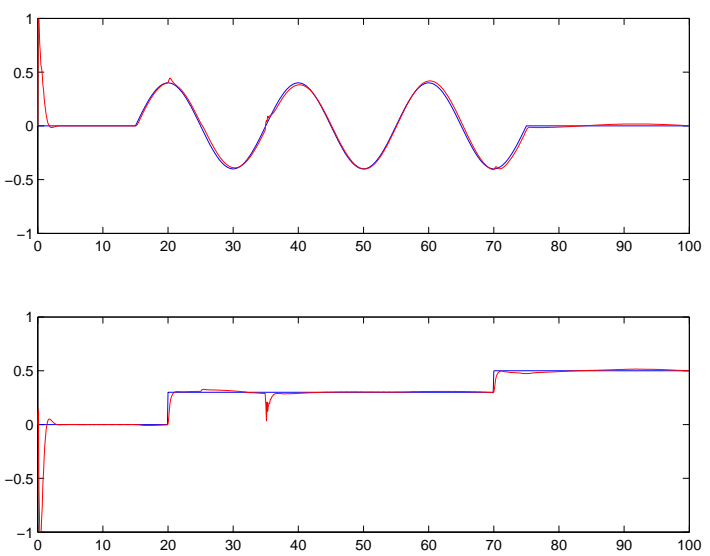

Fig. 4. Actuator faults and their estimation
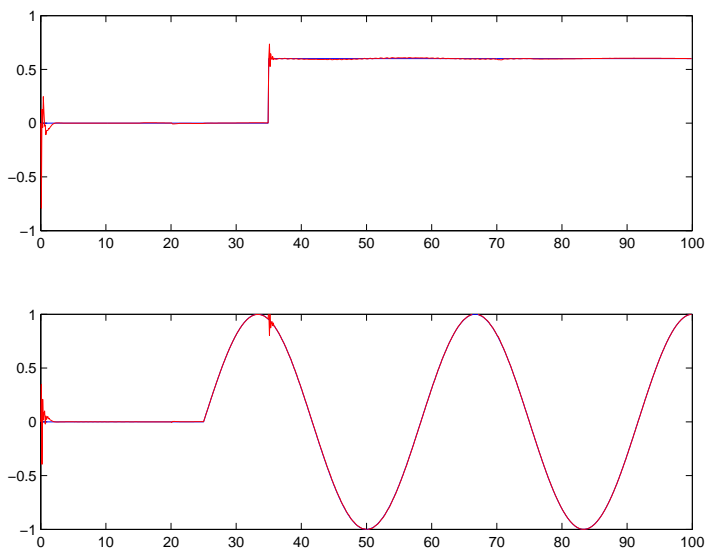

Fig. 5. Sensor faults and their estimation 


\section{REFERENCES}

[1] Akhenak A., Chadli M., Ragot J., Maquin D. Design of sliding mode unknown input observer for uncertain Takagi-Sugeno model. 15th Mediterranean Conference on Control and Automation, MED'07, Athens, Greece, June 27-29, 2007.

[2] Bergsten P., Palm R., Driankov D. Observers for Takagi-Sugeno fuzzy systems. IEEE Transactions on Systems, Man, and Cybernetics - Part B: Cybernetics, 32(1):114-121, 2002.

[3] Edwards C., Spurgeon S.K. On the development of discontinuous observers. International Journal of Control, 59(5):1211-1229, 1994.

[4] Edwards C., Spurgeon S.K. Sliding mode observers for fault detection and isolation. Automatica, 36(6):541-553, 2000.

[5] Edwards C. A comparison of sliding mode and unknown input observers for fault reconstruction. 43rd IEEE Conference on Decision and Control, $\mathrm{CDC}^{\prime} 04$, Atlantis, Paradise Island, Bahamas, December 14-17, 2004.

[6] Guan Y., Saif M. A novel approach to the design of unknown input observers. IEEE Transactions on Automatic Control, 36(5):632-635, 1991.

[7] Ichalal D., Marx B., Ragot J., Maquin D. Simultaneous state and unknown inputs estimation with PI and PMI observers for Takagi-Sugeno model with unmeasurable premise variables. 17th Mediterranean Conference on Control and Automation, MED'09, Thessaloniki, Greece, June 24-26, 2009.

[8] Ichalal D., Marx B., Ragot J., Maquin D. An approach for the state estimation of Takagi-Sugeno models and application to sensor fault diagnosis. 48th IEEE Conference on Decision and Control, Shanghai, P.R. China, December 16-18, 2009.

[9] Khedher A., Benothman K., Maquin D., Benrejeb M. An approach of faults estimation in Takagi-Sugeno fuzzy systems Accepted in the $8^{t h}$ ACS/IEEE International Conference on Computer Systems and Applications AICCSA'10, Hammamet, Tunisia, May 16-19th, 2010

[10] Khedher A., Benothman K., Maquin D., Benrejeb M. Sensor faults estimation for nonlinear systems described by multiple models Accepted for publication in the journal: Transaction on Systems Signals \& Devices.

[11] Khedher A., Benothman K., Maquin D., Benrejeb M. State and sensor faults estimation via a proportional integral observer. 6th International Multi-conference on Systems Signals \& Devices SSD'09, Djerba, Tunisia, March 23-26, 2009.
[12] Khedher A., Benothman K., Maquin D., Benrejeb M. State and unknown input estimation via a proportional integral observer. 9th international conference on Sciences and Techniques of Automatic control and computer engineering STA'2008, Sousse, Tunisia, December 20-23, 2008.

[13] Kobayashi N., Nakamizo T. An observer design for linear systems with unknown inputs. Internation Journal of Control, 35(4):605-619, 1982.

[14] Kudva P., Viswanadham N., Ramakrishna A. Observers for linear systems with unknown inputs. IEEE Transactions on Automatic Control, 25:113-115, 1980

[15] Luenberger D.G. An introduction to observers. IEEE Transactions on Automatic Control, 16(6):596-602, 1971.

[16] Lyubchik L.M., Kostenko Y.T. The output control of multivariable systems with unmeasurable arbitrary disturbances - The inverse model approach. European Control Conference, ECC93, Gröningen, The Netherlands, June 28 - July 1, 1993.

[17] Murray-Smith R., Johansen T. Multiple model approaches to modeling and control. Taylor and Francis, London, 1997.

[18] Orjuela R., Marx B., Ragot J. and Maquin D., On the simultaneous state and unknown inputs estimation of complex systems via a multiple model strategy. IET Control Theory \& Applications, 3(7):877-890, 2009.

[19] Orjuela R., Marx B., Ragot J. and Maquin D., Proportional-Integral observer design for nonlinear uncertain systems modelled by a multiple model approach, 47th IEEE Conference on Decision and Control, Cancun, Mexico, December 9-11, 2008

[20] Sharma R., Aldeen M. Estimation of unknown disturbances in nonlinear systems. Control 2004, University of Bath, UK, September 6-9, 2004.

[21] Thau F.E. Observing the state of non-linear dynamic systems. International Journal of Control, 17(3):471-479, 1973.

[22] Walcott B.L., Zak S.H. Observation of dynamical systems in the presence of bounded nonlinearities/uncertainties. 25th IEEE Conference on Decision and Control, Athens, Greece, December 10-12, 1986.

[23] Wang S.H., Davison E.J., Dorato P. Observing the states of systems with unmeasurable disturbances. IEEE Transactions on Automatic Control, 20:716-717, 1975.

[24] Zhang K., Jiang B., Coquempot V. Adaptive observer-based fast fault estimation. International Journal of Control, Automation, and Systems, 6(3):320-326, 2008 